\title{
Status assessment of the Critically Endangered Azores Bullfinch Pyrrhula murina
}

\author{
RICARDO S. CEIA, JAIME A. RAMOS, RUBEN H. HELENO, GEOFF M. \\ HILTON and TIAGO A. MARQUES
}

\section{Summary}

The Azores Bullfinch is endemic to the island of São Miguel (Azores, Portugal). Its status was uplisted to Critically Endangered in 2005 on the basis of an extremely small and declining population that was considered to be restricted to a very small mountain range $\left(43 \mathrm{~km}^{2}\right)$, in a single location, within which the spread of invasive plants constituted a threat to habitat quality. Nevertheless, information was mostly inferred, or the product of, non-systematic studies. In order to carry out a complete assessment of the conservation status we analysed: (i) population trend, calculated from annual monitoring 1991-2008, (ii) population size, and (iii) range size, obtaining estimates in a single morning study in 2008 involving the simultaneous participation of 48 observers. Contrary to previous inferences, the population is no longer decreasing, although quality of laurel forest habitat continues to decline due to the persistent threat of invasive species. Population size (mean $\pm \mathrm{SE}$ ) was estimated at $1,064 \pm 304$ individuals using distance sampling methods, although the estimate was very sensitive to the survey method used. Range size estimates (extent of occurrence and area of occupancy) were $144 \mathrm{~km}^{2}$ and $83 \mathrm{~km}^{2}$ respectively. Given the present information, we propose the downlisting of Azores Bullfinch to Endangered on the IUCN Red List.

\section{Introduction}

The Azores Bullfinch Pyrrhula murina is one of the only two 'Critically Endangered' bird species that breed in Europe (BirdLife International 2009). It is endemic to the eastern part of the island of São Miguel in the Azores Islands, Portugal (Ramos 1993; Figure 1), where it is closely associated with native laurel forest (Ramos 1996, Ceia et al. 2009). The population is believed to have declined substantially in the second half of the $2 \mathrm{O}^{\text {th }}$ century as a result of severe habitat alterations (LeGrand 1982, Bibby and Charton 1991, Ramos 1996). Firstly, the majority of the laurel forest was cleared in the 1960s for afforestation with the exotic coniferous tree Cryptomeria japonica. More recently, remaining laurel forest areas have been heavily invaded by aggressive exotic plants (Clethra arborea, Hedychium gardneranum and Pittosporum undulatum) which in many areas entirely overwhelm native trees and shrubs (Silva and Smith 2004). Moreover, introduced mammals (Mus musculus, Rattus rattus and Mustela sp.) may feed on eggs and nestlings (Sanches 2008), but their importance as a threat is unknown. In 2005, the Azores Bullfinch was uplisted to 'Critically Endangered', because recent records indicated an extremely small range (extent of occurrence $43 \mathrm{~km}^{2}$, area of occupancy $6 \mathrm{~km}^{2}$ ), and a population decline was inferred because of visible deterioration in habitat quality through invasion of exotic plants (SPEA 2007). The population was tentatively estimated in the low hundreds of individuals (Ramos 1996). However, direct, systematic and quantitative estimates of range size, population trend and population size were lacking, making accurate Red List assessment difficult. 


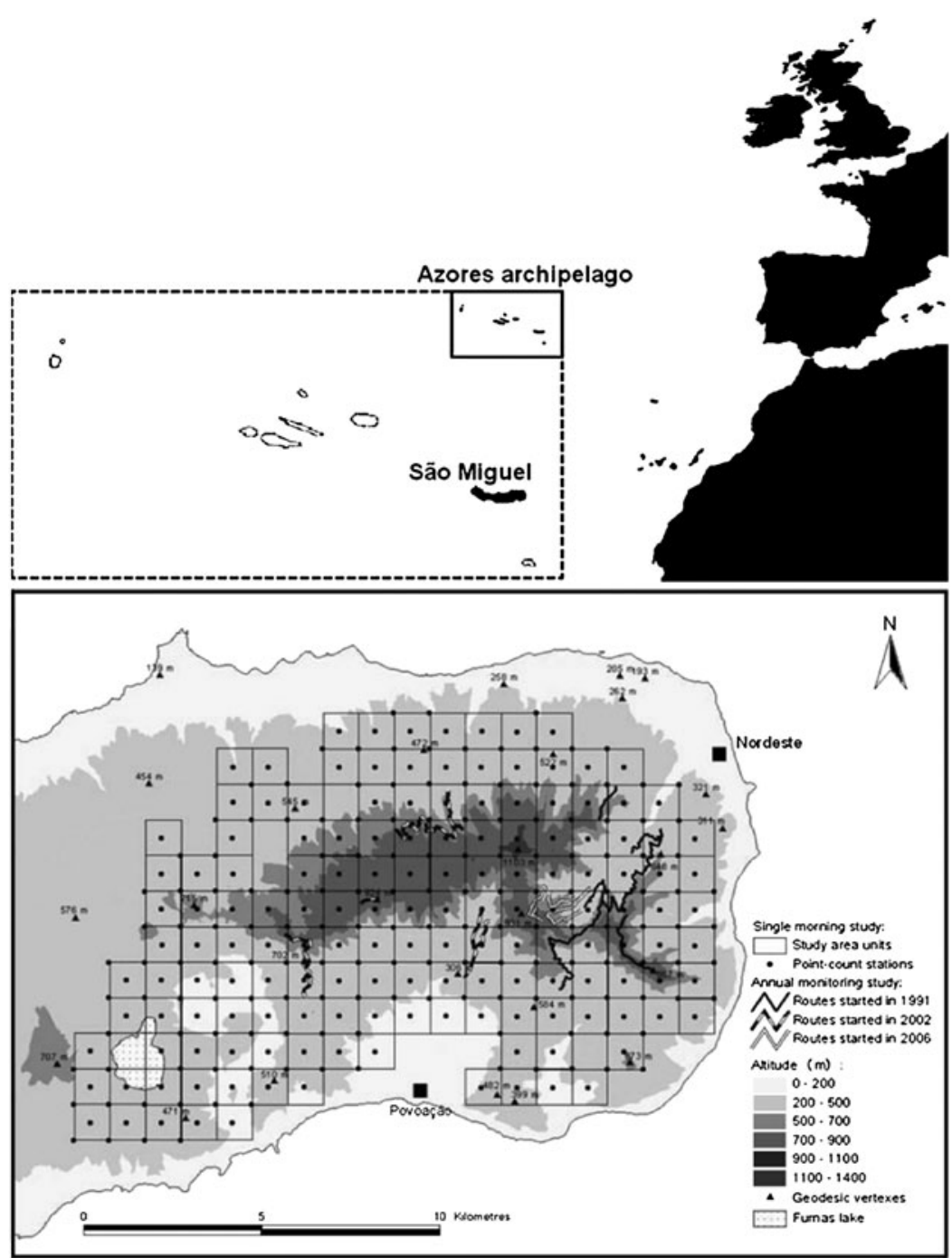

Figure 1. Location of the study area in the eastern part of São Miguel Island, Azores (Portugal). Point-count stations and study area units used in the single morning study are represented, as well as routes used in the annual monitoring study, along which point-counts were set at $200 \mathrm{~m}$ intervals.

Recent programmes of laurel forest restoration (2003-2012) through invasive plant clearance have potentially created the opportunity for the partial recovery of the Azores Bullfinch population. These programmes have also improved access to the extremely mountainous terrain and generated resources to allow surveys of the whole range of the species for the first time.

Here we report on studies of Azores Bullfinch population size, population trend and range size to allow, for the first time, a complete assessment of its conservation status and appropriate Red List category. We also consider whether there are any early indications of population recovery due to habitat management. 


\section{Methods}

Two distinct surveys were conducted in order to measure relevant variables for conservation assessment. Population trend was obtained through a long-term annual monitoring study, while population size and range size were obtained in a single morning survey.

Fieldwork was carried out in the eastern part of São Miguel $\left(37^{\circ} 47^{\prime} \mathrm{N}, 25^{\circ} 13^{\prime} \mathrm{W}\right)$ in the Azores archipelago (Figure 1). Located in the central North Atlantic Ocean, the Azores are characterised by a temperate oceanic climate with small annual temperature range, moderate rainfall spread evenly throughout the year and high relative humidity (Silva and Smith 2004). Nevertheless, all fieldwork was carried out in the absence of rain or heavy mist.

\section{Population trend}

Annual monitoring of Azores Bullfinch population trend started in 1991, although there was a hiatus from 1997 to 2001 . Point-counts were chosen as the sampling method, since line transects are impractical in the very steep and uneven terrain. Point-count stations were set at approximately $200 \mathrm{~m}$ intervals along non-random routes within areas of known occurrence of Azores Bullfinch, encompassing five distinct habitats (laurel forest, margin of laurel forest, marginal areas of $C$. japonica or $P$. undulatum less than $500 \mathrm{~m}$ away from the nearest patch of laurel forest and active raised bogs). Five routes were initially defined comprising 99 point-count stations which were used from 1991 to 1996. In 2002, four new routes were added, although the number of point-count stations on each route varied over the next four years totalling 146, 164, 153 and 153 point-counts, respectively. In 2006, a new route was added, setting the number of point-count stations to 192, distributed along 10 routes.

Point-counts were conducted between o6h3o and IIhoo hrs GMT-1 during the breeding season (19 May-22 August, median date 29 June). Typically, point-count durations in passerine surveys vary between 1 and $5 \mathrm{~min}$ (Ralph and Scott 1981). In order to increase the chance of detecting birds, spot counts of $8 \mathrm{~min}$ were used in this study. To further ensure the detection of birds, counts were made following one minute whistling an imitation of the bird's call. All Azores Bullfinches heard or seen during the counting period were recorded.

\section{Population size and range size}

Study area and survey design

A grid of UTM I x I km units was superimposed on a preliminary spatial distribution of nonsystematic Azores Bullfinch occurrence records, obtained monthly since June 2005 (SPEA 2007, RSC pers. obs.). The resulting study area covered 15,200 ha ( 152 units). This included all the units with previous records and a buffer of $1 \mathrm{~km}^{2}$ units around them, but excluding some buffer units which had clearly inadequate habitat (Ramos 1995, 1996, Ceia et al. 2009). Although ranging from 40 to $1,105 \mathrm{~m}$ a.s.l. (Figure 1 ), most sampled habitats were in mountainous areas with steep ground and were densely vegetated with native and exotic flora $(C$. japonica plantations, P. undulatum copses, laurel forest at various stages of invasion by $C$. arborea and $H$. gardneranum, Macaronesian heaths and active raised bogs) but some anthropogenic habitats were also sampled (pastures, agricultural fields and urban limits).

Point-counts were chosen as the sampling method to estimate the extent of occurrence, area of occupancy and population density. A systematic design was used, setting count stations at the corners and centre of each grid unit (Figure 1 ), totalling 307 point-count stations. Each station was nominally $700 \mathrm{~m}$ from the closest adjacent station. However, in order to ease logistics and ensure observer safety in very steep and difficult terrain, some point-count stations were not conducted at the exact grid location. The average distance of the mapped stations to the real point-count station location was $67 \pm 6 \mathrm{~m}$ (mean $\pm \mathrm{SE}$ ). The variable circular plot method (VCPM; Reynolds et al. 
1980), involving the measurement or estimation of the distance from the observer to each detection during a finite counting period, was used. All aural and visual detections of Azores Bullfinch were recorded as the horizontal distance to the observer at time of first detection. Based on previous knowledge that birds would rarely be double counted because there would be few records per station, 8-min point-counts were used to assess population and range size. Observers also waited one minute after arriving at each station but did not use imitations of the bird's calls to attract them. The few bullfinches flushed by the arrival of observers at the station were recorded in the counts and a distance estimate made to the point from which they departed. A quick count of birds after a prescribed waiting period, rather than the use of a standard counting time period, has been suggested by Buckland et al. (2001) to yield a "snapshot" or instantaneous recording of birds more in line with the underlying assumptions of distance sampling. Following these recommendations, a parallel snapshot survey was conducted and the "snapshot" moment defined as precisely five minutes after arrival at the point.

The approximate location of all birds located during the counts was recorded, either on maps or using GPS equipment. Birds heard or seen outside the counting period, e.g. while moving between stations, were also recorded to enhance a precise delimitation of the extent of occurrence and area of occupancy.

\section{Training}

Forty-eight observers were recruited in order to complete fieldwork in a single morning (from o6h30 to 1 I hoo hrs GMT-1 on 26 June 2008). A full training programme involving Azores Bullfinch identification, survey methods and data recording, with an emphasis on distance estimation, was undertaken by all observers during the week preceding the census. Field training on distance estimation to visual and aural cues in forest was complemented by specific training exercises which improved observers' ability to estimate distances and allowed an evaluation of their accuracy. These exercises consisted of six simulated point-count stations, around which five coloured tape marks were placed at known horizontal distances relatively close to the recorder $(\mathrm{o}-25 \mathrm{~m})$. At each station, observers noted the estimated distance to marks. Errors in estimated distances decreased along the six simulated point-counts, ending at $11.9 \% \pm 1.1$ (mean $\pm \mathrm{SE}$ ). During field training, observers paced their distance estimates to improve their accuracy. During fieldwork, after the 8-min count, the distance to each detection was confirmed to the nearest metre by pacing and using a metric tape, unless not allowed by difficult terrain conditions.

\section{Data analysis}

\section{Population trend}

In order to examine the long-term trend in Azores Bullfinch density within the core area, we performed a Generalised Linear Mixed Model (GLMM) using lmer procedure in software R version 2.9.I (R Development Core Team 2009). The response variable was the count of birds at an individual point, assuming a Poisson distribution and log-link function. Fixed explanatory variables were date (days since 1 May) as a linear covariate, year (factor) and habitat (five level categorical variable: laurel forest, margin of laurel forest, $C$. japonica areas, $P$. undulatum areas and active raised bogs). 'Route' and 'point' were used as random intercepts to account for potential spatial autocorrelation in trend and the repeated-measures design (although there was uncertainty that the same exact location was being visited in each year). Covariance parameter estimates for the route and point effects were not large or significantly different from zero (route $0.10 \mathrm{SD}=0.31$, point $0.25 \mathrm{SD}=0.50$ ) but were retained as they reflect the underlying structure of the data. There was no indication of a date effect $(P=0.16)$, so the date term was dropped and abundance was modelled as a function of the year and habitat factors which were significant. The 
coefficient estimates for each significant variable were back-transformed producing an annual population index, which is interpreted as the number of birds per point.

\section{Population size}

Data from the VCPM (8-min and snapshot survey datasets) were analysed using the program DISTANCE version 5.0 (Thomas et al. 2010) to calculate densities (individuals ha ${ }^{-1}$ ). Analysis of distance sampling data consisted of three steps: exploratory analysis, model fitting and selection, and model inference. Exploratory graphical analysis of raw detection data was performed using frequency histograms, to illustrate overall detection patterns and identify potential problems such as evasive movements, heaping, and outliers (Buckland et al. 1993). Available key functions (uniform, half-normal, hazard-rate and negative exponential) were tested with cosine series expansion. The selection of a suitable detection function was guided by Akaike's Information Criterion (AIC) in 8-min data analysis, or the version of AIC corrected for small sample size in snapshot survey data analysis (Akaike 1974, Burnham and Anderson 2002), $\chi^{2}$ model-fit statistics, and visual inspection of detection probability and probability density plots (Buckland et al. 2001). An absolute population size estimate was obtained by multiplying computed density estimates by the total sampled area $(15,200 \mathrm{ha})$.

\section{Range size}

As suggested by IUCN (2001), the extent of occurrence of Azores Bullfinch population was calculated by a minimum convex polygon (the smallest polygon in which no internal angle exceeds 180 degrees) containing all locations where birds were recorded during this single morning study and records previously obtained in a non-systematic way between June 2005 and June 2008 (SPEA 2007, RSC pers. obs.). The area of occupancy of this species during the single morning study was calculated as the sum of the occupied UTM $1 \mathrm{~km}^{2}$ units used in the survey design, as this seemed to be an appropriate scale to relevant biological aspects of the Azores Bullfinch, the nature of threats and the available data.

\section{Results}

\section{Population trend}

1,786 counts at 220 points on 10 routes were used in the analysis. Figure 2 shows the population index for the period 1991-2008. Values during the period 2002-2005 were slightly higher than those from 1991-1996 and were followed by a sharp increase - more than a doubling - between 2005 and 2006. The periods 1991-1996, 2002-2005 and 2006-2008 were characterised by steady declines from a peak. Overall, the population index in 2006-2008 was approximately three times the value in 1991-1996.

\section{Population size}

\section{Exploratory analysis}

Ninety Azores Bullfinches were detected at 48 point-count stations, using the VCPM. Observations were continuous during the 8-min counting period with $20,15,6,10,12,9,12$ and 6 first detections in minutes $1-8$, respectively. The snapshot survey data set (i.e. $5^{\text {th }}$ minute after arrival) consisted of 26 observations. Preliminary exploratory analysis showed a typical 'falloff' in detection with distance and an initial increase of histogram frequencies with distance, until the decline in detectability at larger distances outweighed the increase in area surveyed (Figure 3 ). In both sets, maximum detection distance was $300 \mathrm{~m}$, but, as with most studies, there was a long 


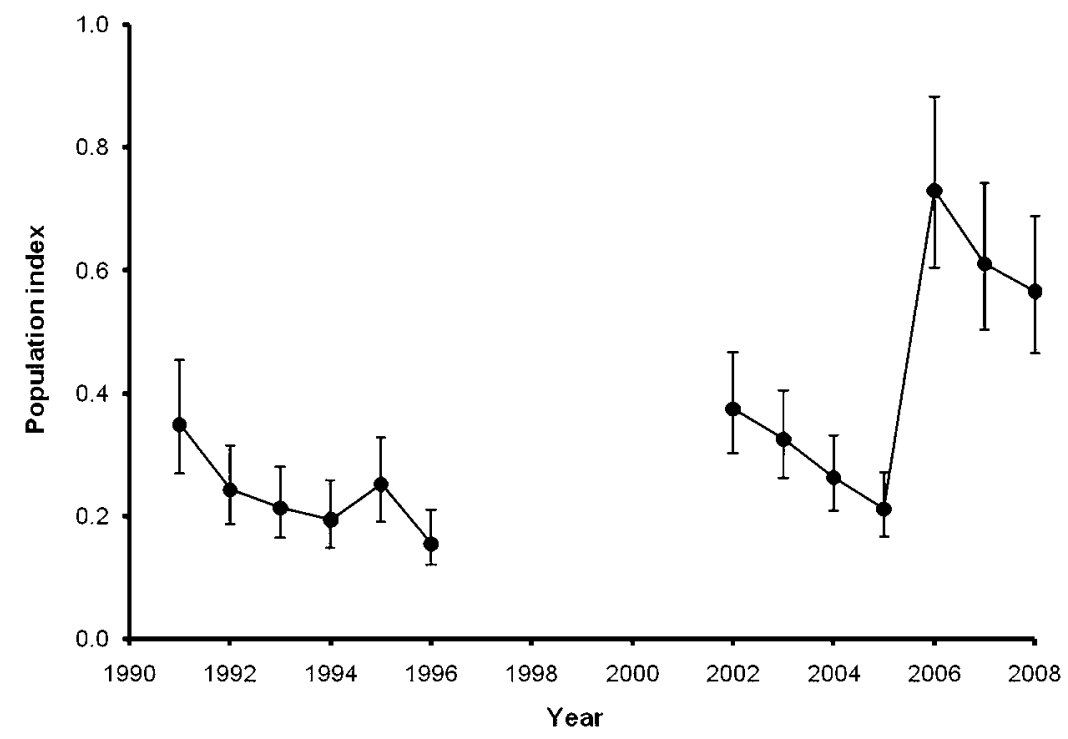

Figure 2. Azores Bullfinch population trend 1991-2008. Annual counts of birds per point were modelled using a Generalised Linear Mixed Model to obtain population index. Error bars represent SE.

tail of larger distances, and the mean distances were $56.1 \mathrm{~m}$ and $73.8 \mathrm{~m}$, for the 8 -min and the snapshot survey datasets respectively.

There was some evidence of rounding distances to preferred values (e.g. nearest 5 and $10 \mathrm{~m}$ ) but after initial inspection it was not believed that this would influence the results (except in reducing the goodness-of-fit of detection functions). The analysis of the goodness-of-fit and the coefficient of variation of several exploratory analyses with different truncation values, indicated that $95 \mathrm{~m}$ was an adequate truncation point for the 8-min data set whilst for the snapshot survey a suitable truncation point was $100 \mathrm{~m}$. Distance estimation in the field is often difficult and inaccurate, and some authors (Verner 1985 among others) consider that it is more plausible for observers to use only a few distance categories still enabling good data modelling in a distance sampling context (Buckland et al. 2001). To test this, we reanalysed both data sets grouped into four distance categories $(0-25,25-50,50-75$ and $75-100 \mathrm{~m})$.

\section{Model fitting and selection}

A minimum of 60 observations is recommended to estimate density with a reasonable degree of accuracy (Buckland et al. 2001). However, we ran the snapshot survey analysis with as few as 22 observations (data truncation at $100 \mathrm{~m}$ ), acknowledging the lower reliability of these results. A $\chi^{2}$ test indicated that all models had a good fit and none of the four critical assumptions of distance sampling was seriously violated (Lloyd et al. 1998; Table 1). Based on lower AIC, the negative exponential detection function best-fitted the truncated 8-min data set outputting an estimate of 1.09 birds ha ${ }^{-1}(\mathrm{SE}=0.28)$ and when analysing grouped data, a density estimate of 1.02 birds ha $^{-1}(\mathrm{SE}=$ 0.65) was obtained when fitted with the hazard-rate function. Densities were considerably lower for the snapshot survey data set. While truncated data best-fitted the uniform distribution with cosine adjustments of first order allowing an estimate of 0.07 birds ha $^{-1}(\mathrm{SE}=0.02)$, grouped data fitted the negative exponential function better, yielding an estimate of $0.23 \mathrm{birds}^{\mathrm{h}^{-1}}(\mathrm{SE}=0.1 \mathrm{I})$. 

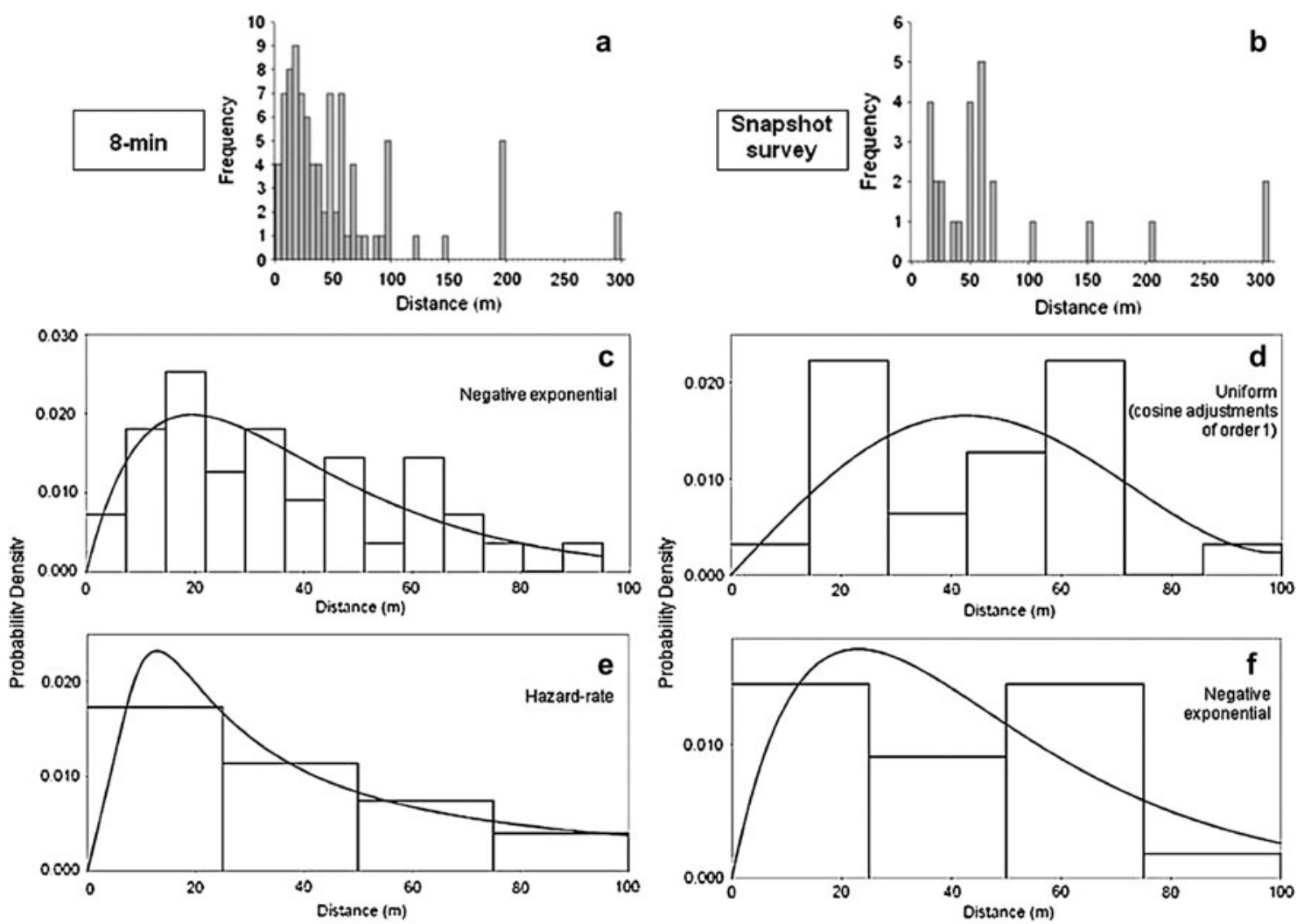

Figure 3. Frequency histograms of distance data (8-min and snapshot survey) for the Azores Bullfinch. Each data set consists of three graphs representing: $(a-b)$ all radial distances at which birds were detected during the survey; estimated probability density function of detected distances, superimposed over the histogram of ungrouped (c-d) and grouped distance data (e-f). See Table $\mathrm{I}$ for details on the key function and series adjustments of each model. 
Table 1 . Density estimates computed with DISTANCE software using data from the variable circular plot method (8-min and snapshot survey data sets). Detections beyond the truncation distance were ignored in the analysis. Although distance data were collected as exact distances, both data sets were reanalysed using four distance categories $(0-25,25-50,50-75$ and $75-100 \mathrm{~m})$. Series expansion order (cosine adjustments) for each key function is shown in brackets. CI - Confidence intervals. CV - Coefficient of variation.

\begin{tabular}{|c|c|c|c|c|c|c|c|}
\hline Data filter & $\begin{array}{l}\text { No. of } \\
\text { observations }\end{array}$ & $\begin{array}{l}\text { Density } \\
\text { (birds ha }{ }^{-1} \text { ) }\end{array}$ & Key function & $\% \mathrm{CV}$ & $95 \%$ & $\mathrm{CI}$ & $P\left(\chi^{2}\right)$ \\
\hline \multicolumn{8}{|l|}{$8-\min$} \\
\hline Truncation-95 m & 76 & 1.09 & Negative exponential & $25 \cdot 47$ & 0.67 & 1.79 & 0.41 \\
\hline Grouped data & 81 & 1.02 & Hazard-rate & 63.84 & 0.32 & 3.24 & 0.56 \\
\hline \multicolumn{8}{|l|}{ Snapshot survey } \\
\hline Truncation-100 m & 22 & 0.07 & Uniform (I) & 28.05 & 0.04 & 0.12 & 0.05 \\
\hline Grouped data & 22 & 0.23 & Negative exponential & 46.22 & 0.10 & 0.56 & 0.11 \\
\hline
\end{tabular}

\section{Model inference}

Based on the coefficient of variation, it was decided to use both non-grouped density estimates in the model inference stage. The Azores Bullfinch population size estimates ( $95 \% \mathrm{CI}$ ) obtained from the 8-min point-counts and the snapshot survey results are $16,568(10,184-27,208)$ individuals and 1,064 $(608-1,824)$ individuals respectively. Snapshot results were preferred over 8-min results (see methodological issues section in Discussion for details) and consequent discussion of results conforms with that estimate.

\section{Range size}

\section{Extent of occurrence}

In the morning of 26 June 2008, there were 422 individual records of Azores bullfinches. These included observations during the 8-min point-counts (9o records) and when moving to or between stations ( 332 records). On the basis of the spatial distribution of these records, an extent of occurrence was delimited with a perimeter of $47,310 \mathrm{~m}$ and an area of 13,738 ha (Figure 4). However, three previously known sites were not encompassed by this calculation (SPEA 2007, RSC pers. obs.). The extent of occurrence of the Azores Bullfinch was recalculated to include those records, resulting in a perimeter of $47,557 \mathrm{~m}$ and an area of 14,444 ha (Figure 4). Although containing some non-sampled areas, the extent of occurrence encompasses the majority (86\%) of the study area.

\section{Area of occupancy}

During the single morning fieldwork, Azores Bullfinch was detected in 83 of the 152 sampling units $(55 \%)$ corresponding to an area of occupancy of 8,255 ha within the calculated extent of occurrence ( $57 \%$ of the total extent of occurrence).

\section{Discussion}

This study provides the first comprehensive assessment of what was hitherto regarded as Europe's most threatened songbird. The results indicate that the status of the Azores Bullfinch is not as perilous as was imagined in the 1990s, and furthermore that there is evidence of recent population recovery. However, the species continues to occur only in a single, small mountain range, and must therefore be considered susceptible to stochastic or anthropogenic events that might cause rapid population reduction. 


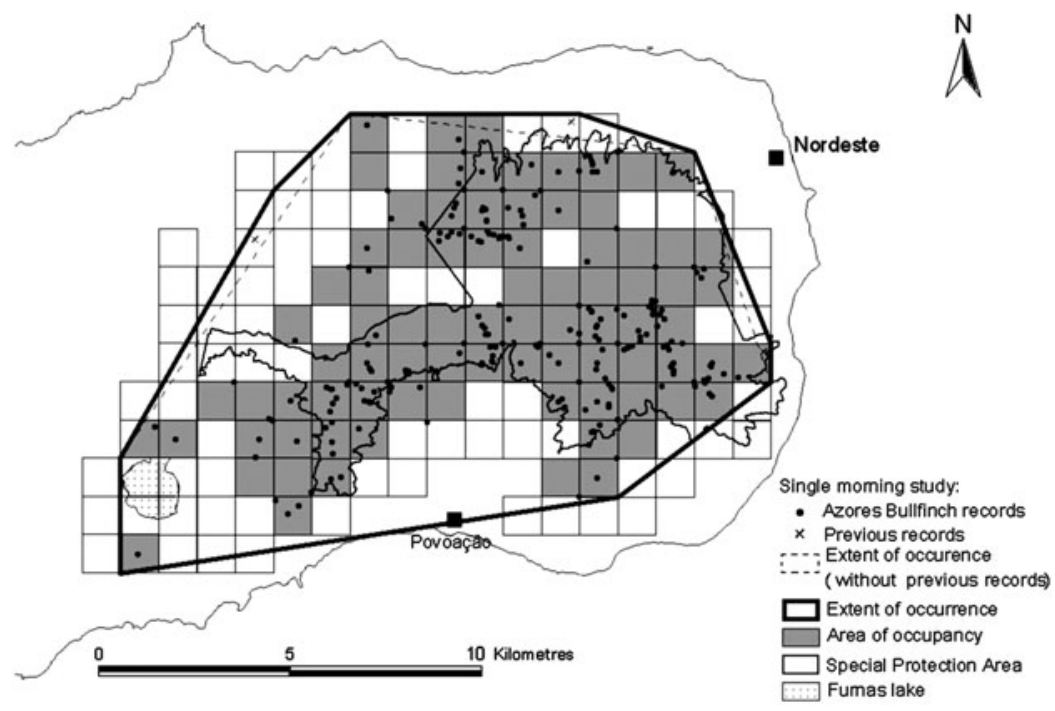

Figure 4. Extent of occurrence comprising all Azores Bullfinch locations during the single morning study and three additional locations where the species was recorded prior to this study (between June 2005 and June 2008). Area of occupancy is represented by the $1 \mathrm{~km}^{2}$ units with Azores Bullfinch locations during the single morning study.

Despite improving population size estimates so far, snapshot survey data analyses were carried out with a low sample size. New snapshot surveys should be conducted in the near future with increased sampling effort, allowing a reasonable sample size for robust detection function to be estimated. Detections from multiple years might be used to estimate a pooled detection function. Further, a year covariate might be added if trends in detectability are expected over time.

\section{Red List assessment}

This status assessment indicates that the Azores Bullfinch is a candidate for downlisting on the Red List. Its range is larger than previously estimated, its population higher and the population trend does not appear to have been negative since 1995 .

An extent of occurrence of $\sim 140 \mathrm{~km}^{2}$ is approximately three times larger, and an area of occupancy of $83 \mathrm{~km}^{2}$ is over 10 times larger than previously estimated (BirdLife International 2009). Thus range size does not appear to meet the threshold for 'Critically Endangered' under criterion B. The population size estimate of $\sim 1$, 000 individuals yielded by the snapshot survey, is also far greater than the 200-300 birds estimated in 2002-2005, based on partial census coverage and informal extrapolation, and exceeds the threshold for 'Critically Endangered' under criterion C.

Of even greater importance is the new analysis of population trend, which suggests that the inference of ongoing population decline due to progressive habitat degradation is not correct. Contrary to expectation, the GLMM suggests no decline between the early 199os and the early 2000s, and a marked increase in 2006-2008. The stable or increasing population over more than 15 years, coupled with an absence of extreme fluctuations also indicated by the monitoring data, apparently imply that Red List criteria B and C are not triggered, leading to a classification of the Azores Bullfinch as 'Vulnerable' under criterion D2 (restricted population). However, a precautionary approach is appropriate. Invasive species continue to spread elsewhere within the 
range of the species and although population trend is not apparently affected, the species has a preference for non-invaded laurel forest habitat (Ramos 1995, 1996, Ceia et al. 2011), and is entirely absent from highly invaded areas (e.g. P. undulatum copses; Ceia et al. 2009). This continuing deterioration of habitat quality together with the restricted range in one location triggers criterion B. Therefore, we suggest that the Azores Bulfinch qualifies as 'Endangered' in the 2010 IUCN Red List under criteria $\mathrm{B}_{1} \mathrm{a}+\mathrm{b}(\mathrm{iii})$ and $\mathrm{B} 2 \mathrm{a}+\mathrm{b}(\mathrm{iii})$.

\section{Methodological issues}

Conceptually, distance sampling bird point-count censuses represent instantaneous 'snapshots' of the birds present and detected at the plot (Buckland et al. 2001). Most counts are completed over several minutes for practical reasons, despite known problems with the density estimates being biased high (Buckland et al. 2008 and references therein). However, the suggestion has been made that using a genuine snapshot approach, following a settling-in period, can overcome these problems (Buckland 2006). In the case of the Azores Bullfinch, a snapshot approach is particularly appealing for two main reasons. Firstly because it is a relatively mobile bird, giving high potential for over-estimating density with prolonged count periods. Secondly because the census was directed at a single, easily identifiable species, observers could relatively successfully determine the locations of individuals prior to the snapshot.

Our data show enormous disparities between the snapshot and the timed-count approaches, with the latter producing estimates that were more than an order of magnitude higher than the former. The apparent good fit of the negative exponential model to the data further suggests problems with the 8-min data (e.g. Buckland 1985), as it is hard to imagine a search pattern such that all birds on the point are detected but a large proportion are missed just off it, which the absence of a shoulder and the steep slope of the negative exponential both imply. We suggest that the snapshot approach produced the more realistic estimate (despite the much smaller sample size) because it avoids the biases described above - which are particularly acute for this species - and because independent estimates of population size based on capture-mark-recapture yielded similar results (mean \pm SE: $1608 \pm 326$ individuals; Monticelli et al. 2010). This study strongly supports the use of the snapshot approach where it is practicable.

\section{Conservation}

\section{SPA designation}

One notable aspect of the 2008 single morning study was to demonstrate that the current EU Special Protection Area of Pico da Vara / Ribeira do Guilherme actually includes only about 60\% of the Azores Bullfinch range, despite the species being the main trigger for the site's designation. This is not because the SPA is poorly located, since it encompasses $87 \%$ of the records (368 out of 422) and very little falls outside the area of occupancy, but rather because the SPA is about half of the extent of occurrence as now measured. In fact the SPA was tripled in size to its current 6,067 ha only in 2005, specifically to encompass known Azores Bullfinch areas and apparently suitable laurel forest. Substantial further expansion of the SPA seems unwarranted at present, because habitat mapping indicates that it already contains the great majority $(1,675$ ha of 2,013 ha) of the optimal laurel forest habitat, whereas the occupied areas outside the SPA tend to be lower quality habitats such as Macaronesian heaths, active raised bogs and pastures which support lower population densities (authors' pers. obs.).

\section{Habitat management}

The suggestion in the monitoring data that population density in core areas increased markedly from 2006 onwards implies that the unexpectedly large range size and population estimate derived 
from the 2008 single morning study might partly arise from a genuine recent increase and expansion, rather than previous underestimates. It seems extremely improbable that the massive destruction of laurel forest for conifer plantations in the 196os did not cause a very large population decline as recent data clearly show that the species is almost entirely absent from such plantations (Ceia et al. 2009). Since the very abrupt creation of the plantations, the remaining native forest has suffered an extreme invasion by a few exotic plant species. Contrary to the predictions of Ramos (1996), monitoring data indicate that this was accompanied by further population increase - at least since the early 199os. It is not clear why this should be so. Two of the invasive plant species, H. gardneranum and P. undulatum, are virtually unused by the Azores Bullfinch (Ramos 1995, Ceia et al. 2011), but have become overwhelmingly dominant in parts of the forest, greatly reducing the food available from native plants (Heleno et al. 2009, 2010, Ceia et al. 2011). The other abundant invasive plant, C. arborea, is a different case, as its seeds are heavily used by bullfinches between December and February (Ramos 1995, Ceia et al. 2011). This is a season when native fruits and seeds are severely depleted (Ramos 1995), although this depletion appears to be greatly accentuated by the suppression of native plants by invasives (Ceia et al. 2011). Potentially, the spread of $C$. arborea has replaced native food sources sufficiently to allow the Azores Bullfinch population to remain stable.

Also intriguing is the unprecedented rapid increase after 2005. Both the timing and nature of the laurel forest restoration work from 2003 to the present suggests that it is unlikely to be the cause of the Azores Bullfinch increase (although the work was predicated on such an increase occurring in the future). By summer 2006 during which the census took place, only 53 ha of forest had been cleared of invasive plants. By 2008, the cleared total had increased to 204 ha. Early indications are that native plants, including Azores Bullfinch food plants, show some recovery within one season of invasive clearance, and that Azores bullfinches do rapidly use cleared areas (Ceia et al. 2011). Conversely, there are some indications that a change in the behavioural ecology of the Azores Bullfinch may have occurred. In some areas, birds have been observed foraging extensively on pastures close to laurel forest, a behaviour not observed in the 1990s. Moreover, in those pastures birds foraged on exotic shrubs and herbaceous plants, such as buds of Hydrangea macrophylla, fruits of Leycesteria formosa and seeds of Persicaria capitata and Prunella vulgaris (authors' pers. obs.). A presumably successful breeding season in 2005 and the estimated high survival rate of the species between 2005 and 2008 (Monticelli et al. 2010) corroborate recent population increase, although there are no other known environmental drivers for the rapid increase. Climate, predation and competition dynamics might have shifted to favour the bullfinch, and thus compensate for habitat degradation; however no data are available to evaluate this. Finally, it is possible that the Azores Bullfinch population lies well below carrying capacity determined by food supply, due to factors such as predation or extreme weather events.

\section{Acknowledgements}

This work was part of the Azores Bullfinch monitoring programme included in the project LIFE NAT/P/oooo13 "Recovery of Azores Bullfinch's habitat in the Special Protection Area of Pico da Vara / Ribeira do Guilherme". We thank all the partners involved and the European Commission for financing this project through the LIFE programme. We thank the Disney Worldwide Conservation Fund for supporting the 2008 census initiative and Royal Society for the Protection of Birds, especially J. Tavares, for submitting the proposal. We thank all the volunteer participants in the 2008 census for their major contribution, without their motivation and interest this study would not be possible: A. Marcelino, A. Bernard, A. de la Cruz, B. Lester, B. Mendonça, C. Gouveia, C. Pereira, C. Silva, C. Vernaz, D. Geraldes, D. Howlett, D. Jareño, D. Patacho, E. Camberlein, F. Azevedo, G. Alphonsine, G. Long, H. Sampaio, J. Benedicto, J. Figueiredo, J-C. Mantellier, J. Sida, J. Tavares, J. Teodósio, L. Alvarez, L. Costa, L. Estrela, L. Girard, L. Vasconcelos, M. Arosa, M. Losada, M. Stieglitz, N. Melo, O. Gurruchaga, 
P. Agostinho, P. Amaral, P. Fernandes, P. Tavares, R. Bastos, R. Botelho, S. Hervías, S. Rocha, S. Sanches, S. Timóteo, T. Valkenburg and V. Coelho.

\section{References}

Akaike, H. (1974) A new look at the statistical model identification. IEEE T. Automat. Contr. 19: 716-723.

Bibby, C. J. and Charlton, T. D. (1991) Observations on the São Miguel Bullfinch. Açoreana 7: 297-304.

BirdLife International (2009) Pyrrhula murina. In: IUCN (2010) IUCN Red List of Threatened Species. Version 2010.1. Downloaded from http://www.iucnredlist.org. on 10/5/2010.

Buckland, S. T. (1985) Perpendicular distance models for line transect sampling. Biometrics 41: 177-195.

Buckland, S. T. (2006) Point-transect surveys for songbirds: robust methodologies. Auk 123: 345-357.

Buckland, S. T., Anderson, D. R., Burnham, K. P. and Laake, J. L. (1993) Distance sampling: Estimating abundance of biological populations. London, UK: Chapman \& Hall.

Buckland, S. T., Anderson, D. R., Burnham, K. P., Laake, J. L., Borchers, D. L. and Thomas, L. (2001) Introduction to distance sampling: Estimating abundance of biological populations. Oxford, UK: Oxford University Press.

Buckland, S. T., Marsden, S. J. and Green, R. E. (2008) Estimating bird abundance: making methods work. Bird Conserv. Internatn. 18: S91-S108.

Burnham, K. P. and Anderson, D. R. (2002) Model selection and multimodel inference: A practical information-theoretic approach. 2nd edition. New York, USA: Springer-Verlag.

Ceia, R., Heleno, R. and Ramos, J. A. (2009) Summer abundance and ecological distribution of passerines in native and exotic forests in São Miguel, Azores. Ardeola 56: 25-39.

Ceia, R. S., Sampaio, H. L., Parejo, S. H., Heleno, R. H., Arosa, M. L., Ramos, J. A. and Hilton, G. M. (2011) Throwing the baby out with the bathwater: does laurel forest restoration remove a critical winter food supply for the critically endangered Azores bullfinch? Biol. Invasions. 13: 93-104.

Heleno, R. H., Ceia, R. S., Ramos, J. A. and Memmott, J. (2009) The effect of alien plants on insect abundance and biomass: a food web approach. Conserv. Biol. 23: 410-419.

Heleno, R., Lacerda, I., Ramos, J. A. and Memmott, J. (2010) Evaluation of restoration effectiveness: community response to the removal of alien plants. Ecol. Appl. 20: 1191-1203.

IUCN (2001) IUCN Red List categories and criteria: Version 3.1. Gland, Switzerland and Cambridge, UK: IUCN Species Survival Commission.

LeGrand, G. (1982) O Priôlo, a ave mais interessante de São Miguel. Açoreana 6: 195-209.

Lloyd, H., Cahill, A., Jones, M. and Marsden, S. (1998) Estimating bird densities using distance sampling. Pp. 35-52 in C. Bibby, M. Jones and S. Marsden eds. Expedition field techniques: Bird surveys. London, UK: Royal Geographical Society.

Monticelli, D., Ceia, R., Heleno, R., Laborda, H., Timóteo, S., Jareño, D., Hilton, G. M. and Ramos, J. A. (2010). High survival rate of a critically endangered species, the Azores Bullfinch Pyrrhula murina, as a contribution to population recovery. J. Ornithol. 151: 627-636.

$\mathrm{R}$ Development Core Team (2009) R: A language and environment for statistical computing. Vienna, Austria: R Foundation for Statistical Computing. http: \wwww. R-project.org.

Ralph, C. J. and Scott, J. M., eds. (1981) Estimating numbers of terrestrial birds. Lawrence, KA, USA: Cooper Ornithology Society. (Studies in Avian Biology 6).

Ramos, J. A. (1993) Status and ecology of the priolo or Azores Bullfinch, Pyrrhula murina. PhD Thesis. Oxford, UK: Oxford University. 
Ramos, J. A. (1995) The diet of the Azores bullfinch Pyrrhula murina and floristic variation within its range. Biol. Conserv. 71: 237-249.

Ramos, J. A. (1996) Introduction of exotic tree species as a threat to $\mathrm{t}$ he Azores bullfinch population. J. Appl. Ecol. 33: 710-722.

Reynolds, R. T., Scott, J. M. and Nussbaum, R. A. (1980) A variable circular plot method for estimating bird numbers. Condor 82: 309313.

Sanches, S. M. B. S. (2008) Monitorização de roedores e mustelídeos em floresta laurissilva macaronésica e seu impacto na avifauna. MSc Thesis. Coimbra, Portugal: Universidade de Coimbra.

Silva, L. and Smith, C. W. (2004) A characterization of non-indigenous flora of the
Azores Archipelago. Biol. Invasions 6: 193204.

SPEA (2007) Recuperação do habitat do Priolo na ZPE Pico da Vara / Ribeira do Guilherme. LIFE 03NAT/P/oooo13. Relatório de Progresso, I Novembro 2006 a 30 Setembro 2007. Lisboa, Portugal: Sociedade Portuguesa para o Estudo das Aves.

Thomas, L., Buckland, S. T., Rexstad, R., Laake, J. L., Strindberg, S., Hedley, S., Bishop, J., Marques, T. A. and Burnham, K. P. (2010) Distance software: design and analysis of distance sampling surveys for estimating population size. J. Appl. Ecol. 47: 5-14.

Verner, J. (1985) Assessment of counting techniques. Curr. Ornithol. 2: 247-320.

\section{RICARDO S. CEIA*}

Sociedade Portuguesa para o Estudo das Aves (SPEA), Avenida João Crisóstomo $18-4^{\circ}$ Dto., 100o-179 Lisboa, Portugal.

\section{JAIME A. RAMOS}

Institute of Marine Research (IMAR/CMA), Department of Life Sciences, University of Coimbra, P.O. Box 3046, 3001-401 Coimbra, Portugal.

\section{RUBEN H. HELENO}

Institut Mediterrani d'Estudis Avançats (CSIC-UIB), o719o Esporles, Mallorca, Balearic Islands, Spain.

\section{GEOFF M. HILTON}

Royal Society for the Protection of Birds (RSPB), The Lodge, Sandy, Beds, SG19 2DL, UK.

Present address: Wildfowl \& Wetlands Trust, Slimbridge, Glos, GL2 7BT, UK.

\section{TIAGO A. MARQUES}

Centre for Research into Ecological and Environmental Modelling, The Observatory, University of St. Andrews, St. Andrews KY16 9LZ, Scotland.

Centro de Estatística e Aplicações da Universidade de Lisboa, Bloco C6, Piso 4, Campo Grande, 1749-016 Lisboa, Portugal.

*Author for correspondence; e-mail: ricardoceia@gmail.com

Received 28 June 2010; revision accepted 10 December 2010; Published online 11 April 2011 